\title{
Post hoc Analysis of Clinical Outcomes in Placebo- and Pirfenidone-Treated Patients with IPF Stratified by BMI and Weight Loss
}

\author{
Stéphane Jouneau ${ }^{a}$ Bruno Crestani ${ }^{b}$ Ronan Thibault ${ }^{c}$ Mathieu Lederlin ${ }^{d}$ \\ Laurent Vernhet ${ }^{e}$ Ming Yang ${ }^{f}$ Elizabeth Morgenthien ${ }^{f}$ \\ Klaus-Uwe Kirchgaesslerg ${ }^{\mathrm{V}}$ Vincent Cottin ${ }^{\mathrm{h}}$ \\ aDepartment of Respiratory Diseases, Hôpital Pontchaillou, Univ Rennes, INSERM, EHESP, IRSET UMR_S1085, Rennes, \\ France; bepartment of Pulmonology, AP-HP, Hôpital Bichat, FHU APOLLO, Inserm 1152, Université de Paris, \\ Paris, France; 'Unité de Nutrition, CHU Rennes, INRAE, INSERM, Univ Rennes, Nutrition Metabolisms and Cancer, \\ NuMeCan, Rennes, France; dDepartment of Radiology, Univ Rennes, CHU Rennes, INSERM, LTSI, UMR 1099, Rennes, \\ France; 'INSERM, EHESP, IRSET (Institut de recherche en santé, environnement et travail), Univ Rennes, UMR_S1085, \\ Rennes, France; ${ }^{\mathrm{f} G e n e n t e c h, ~ I n c ., ~ S o u t h ~ S a n ~ F r a n c i s c o, ~ C A, ~ U S A ; ~}{ }^{9}$ F. Hoffmann-La Roche, Ltd., Basel, Switzerland; \\ ${ }^{h}$ National Reference Coordinating Center for Rare Pulmonary Diseases, Louis Pradel Hospital and Hospices Civils de \\ Lyon, Université Claude Bernard Lyon 1, UMR754, member of OrphaLung, RespiFil, ERN-LUNG, Lyon, France
}

\section{Keywords}

Body composition · Interstitial lung disease $\cdot$ Idiopathic pulmonary fibrosis · Body mass index

\begin{abstract}
Background: Weight loss is frequently reported in patients with idiopathic pulmonary fibrosis (IPF) and may be associated with worse outcomes in these patients. Objective: The aim of this study was to investigate the relationships between body mass index (BMI) and weight loss, and outcomes over 1 year in patients with IPF. Methods: Data were included from placebo patients enrolled in ASCEND (NCT01366209) and CAPACITY (NCT00287716 and NCT00287729), and all patients in INSPIRE (NCT00075998) and RIFF Cohort A (NCT01872689). An additional analysis included data from pirfenidone-treated patients. Outcomes (annualized change in percent predicted forced vital capacity [\%FVC], percent predicted carbon monoxide diffusing capacity, 6-min walk distance, St. George's Respiratory Questionnaire total score, hospitalization, mortality, and serious adverse events) were analyzed by baseline BMI $\left(<25 \mathrm{~kg} / \mathrm{m}^{2}, 25 \mathrm{~kg} / \mathrm{m}^{2}-<30 \mathrm{~kg} / \mathrm{m}^{2}\right.$,
\end{abstract}

or $\geq 30 \mathrm{~kg} / \mathrm{m}^{2}$ ) and annualized percent change in body weight (no loss, $>0-<5 \%$ loss, or $\geq 5 \%$ loss). Results: Placebotreated patients with a baseline BMI $<25 \mathrm{~kg} / \mathrm{m}^{2}$ or annualized weight loss may experience worse outcomes versus those with a baseline $\mathrm{BMI} \geq 25 \mathrm{~kg} / \mathrm{m}^{2}$ or no weight loss. The proportion of placebo-treated patients who experienced a relative decline of $\geq 10 \%$ in $\% F V C$ or death up to 1 year postrandomization was highest in patients with a baseline BMI $<25 \mathrm{~kg} / \mathrm{m}^{2}$. Pirfenidone-treated patients with an annualized weight loss $\geq 5 \%$ may also experience worse outcomes versus those with no weight loss. Conclusions: Patients with a baseline $\mathrm{BMI}<25 \mathrm{~kg} / \mathrm{m}^{2}$ or annualized weight loss of $>0-<5 \%$ or $\geq 5 \%$ may experience worse outcomes over 1 year versus those with a baseline BMI $\geq 25 \mathrm{~kg} / \mathrm{m}^{2}$ or no weight loss.

$$
\begin{aligned}
& \text { (c) } 2021 \text { The Author(s). } \\
& \text { Published by S. Karger AG, Basel }
\end{aligned}
$$

\section{Introduction}

Idiopathic pulmonary fibrosis (IPF) is a chronic, progressive lung disease that is associated with a survival rate lower than that reported for many cancers [1-4]. Patients
C 2021 The Author(s).

Published by S. Karger AG, Basel

This is an Open Access article licensed under the Creative Commons Attribution-NonCommercial-4.0 International License (CC BY-NC) (http://www.karger.com/Services/OpenAccessLicense), applicable to the online version of the article only. Usage and distribution for commercial purposes requires written permission.
Correspondence to:

Stéphane Jouneau, stephane.jouneau@chu-rennes.fr 
with IPF experience a progressive decline in lung function and exercise capacity, ending in respiratory failure and death; however, the disease course can be variable [ 1 , $2,5,6]$. Identification of potential indicators of disease severity and prognosis in patients with IPF, including those receiving antifibrotic therapy, are therefore active areas of interest $[7,8]$.

Body mass index (BMI) and body weight are routinely assessed in clinical practice, and associations between $\mathrm{BMI}$ and prognosis have been reported in patients with chronic obstructive pulmonary disease and rheumatoid arthritis $[9,10]$. Many patients with IPF experience weight loss, which has been associated with an increased risk of early treatment termination [11] and reductions in transplant-free and overall survival [12-14]. Furthermore, weight loss has been suggested as a longitudinal marker of disease progression and a predictor of mortality in IPF; however, there are limitations associated with these retrospectively acquired data $[12,14]$. Prospective studies evaluating the association between weight loss and poor prognosis in IPF are warranted in the future.

It should be acknowledged that weight loss is only one factor within the wider context of disease-associated malnutrition; however, there are limited clinical studies in IPF that collect detailed data on malnutrition. BMI and weight loss are 2 practical proxies for investigation that can be measured quickly with minimal equipment in clinical practice [15-17]. This post hoc analysis aimed to investigate the relationships between BMI and weight loss and individual clinical outcomes over 1 year in patients with IPF.

\section{Materials and Methods}

\section{Patient Population}

This post hoc analysis included pooled data from 5 randomized controlled trials of patients with IPF (ASCEND [NCT01366209], CAPACITY [NCT00287716 and NCT00287729], INSPIRE [NCT00075998], and RIFF [NCT01872689]). The designs of these trials have been published previously. Briefly, ASCEND and CAPACITY were phase III, double-blind trials of pirfenidone versus placebo $[18,19]$; INSPIRE was a phase III, placebo-controlled trial that evaluated the efficacy of interferon- $\gamma-1 \mathrm{~b}$ [20]; and RIFF (Cohort A) assessed lebrikizumab monotherapy versus placebo in a phase II study [21].

The analysis presented here included patients from the placebo arms of ASCEND and CAPACITY, and all patients from INSPIRE and RIFF (Cohort A). All patients from the INSPIRE and RIFF (Cohort A) trials were included as no treatment effect was detected in the active treatment arms of these trials [20,21]. The lack of treatment difference observed during these trials enabled the inclusion of all patients to provide a larger pooled population than would be obtained by including patients in the placebo group only. Furthermore, the annualized percentage weight change was similar between the 2 treatment groups in each of these studies. An additional analysis included patients who received pirfenidone 2,403 mg/day during ASCEND and CAPACITY (patients who received $1,197 \mathrm{mg} /$ day in CAPACITY 004 were not included in this analysis).

\section{Predictors}

In our post hoc analyses of clinical outcomes at 1 year, patients were stratified by baseline BMI and annualized percent change in body weight. Baseline BMI was categorized based on World Health Organization (WHO) standards, with some categories combined to increase patient numbers per group, as follows: $<25 \mathrm{~kg} / \mathrm{m}^{2}$ (WHO normal weight or underweight), $25 \mathrm{~kg} / \mathrm{m}^{2}-<30 \mathrm{~kg} / \mathrm{m}^{2}$ (WHO preobesity), or $\geq 30 \mathrm{~kg} / \mathrm{m}^{2}$ (WHO obesity, class I-III) [22]. The annualized percent change in body weight was categorized based on the US Food and Drug Administration (FDA) Guidance for Developing Products for Weight Management, which recommends an annualized weight loss of $\geq 5 \%$ for use as a primary endpoint [23]. We adapted this guidance and categorized the annualized percent change in body weight as follows: no loss, $>0-<5 \%$ loss, or $\geq 5 \%$ loss. Weight measurements were collected for patients at site visits during each trial.

\section{Outcomes}

Outcomes assessed in patients from the placebo arms of ASCEND and CAPACITY, and all patients from INSPIRE and RIFF (Cohort A) included annualized changes from baseline in percent predicted forced vital capacity (FVC), percent predicted carbon monoxide diffusing capacity (DLco), 6-min walk distance (6MWD), and the St. George's Respiratory Questionnaire (SGRQ) total score. The proportion of patients with an absolute or relative decline of $\geq 10 \%$ in percent predicted FVC or death up to 1 year post-randomization was evaluated. All-cause hospitalization and mortality were evaluated using time-to-event analyses. Treatmentemergent serious adverse events (SAEs) were also assessed. The same outcomes were assessed in patients from the pirfenidone treatment arms of ASCEND and CAPACITY.

\section{Statistical Analyses}

Baseline demographics and characteristics, stratified by baseline BMI category, were reported descriptively.

For each patient with a baseline and at least one post-baseline measurement of body weight, an annualized percent change in body weight was determined from a linear mixed model for repeated measures of body weight versus actual time since baseline weight assessment (day 1). The model included both random intercept and random slope terms (assuming different change patterns among patients). For each patient, the predicted 1-year weight change was estimated and percent change calculated using the baseline weight. Patients who discontinued or died prior to 1 year were included in the analyses if weight data were available. Any patient with missing baseline weight or no post-baseline measurement was excluded. All available body weights for each patient were included in the repeated-measures model. The proportions of patients with an absolute or relative decline of $\geq 10 \%$ in percent predicted FVC or death up to 1 year post-randomization, stratified by baseline BMI category and annualized percent change in body weight, were reported descriptively. 
Clinical outcomes up to 1 year were presented as estimates (with 95\% confidence intervals [CIs]) and estimated differences (with 95\% CIs), from the reference category. For assessment according to BMI, the reference category was baseline BMI $<25 \mathrm{~kg} /$ $\mathrm{m}^{2}$, and for assessment according to annualized percent change in body weight, the reference category was no weight loss. For continuous data (changes in percent predicted FVC, percent predicted DLco, 6MWD, and SGRQ total score), estimates were based on repeated-measures analysis of covariance, with study, age, sex, race, baseline high-resolution computed tomography status, years since IPF diagnosis, baseline oxygen use, baseline smoking status, the categorical variable of interest (baseline BMI category or annualized percent change in body weight category), time, and annualized categorical variable of interest*time as fixed-effect covariates, with random intercept and random slope for time for each patient. For these outcomes, estimated annual rates of change were obtained for patients who dropped out or died prior to 1 year if the baseline assessment and at least one post-baseline assessment were available. For binary data (any hospitalization, mortality, absolute or relative decline of $\geq 10 \%$ in percent predicted FVC or death, and treatment-emergent SAEs), estimates were based on logistic regression with study, age, sex, race, baseline high-resolution computed tomography status, years since IPF diagnosis, baseline oxygen use, baseline smoking status, and the categorical variable of interest as model factors. For these outcomes, patients who dropped out or died prior to 1 year were categorized based on available data to the point of discontinuation or death.

Time-to-event analyses of first all-cause hospitalization and mortality are also presented by stratified annualized percent change in body weight. Kaplan-Meier curves were used to display event times and the number of patients at risk, which were compared using the log-rank test.

For the analysis population including patients from the placebo arms of ASCEND and CAPACITY, and all patients from INSPIRE and RIFF (Cohort A), a sensitivity analysis was performed for clinical outcomes at 1 year, stratified by annualized percent change in body weight, which excluded patients with no post-baseline body weight measurement after day 90. A sensitivity analysis was also performed for time to first all-cause hospitalization, in which death that occurred without a prior hospitalization event was treated as a competing risk event. Gray's test was used to compare cumulative incidence functions [24].

\section{Results}

\section{Patients}

In total, 1,604 patients from the placebo arms of ASCEND and CAPACITY and both treatment arms of INSPIRE and RIFF (Cohort A) were included in the main analysis population, with a mean (standard deviation) baseline BMI of 29.68 (4.70) kg/m² (baseline BMI: $<25 \mathrm{~kg}$ / $\mathrm{m}^{2}, n=227 ; 25 \mathrm{~kg} / \mathrm{m}^{2}-<30 \mathrm{~kg} / \mathrm{m}^{2}, n=703 ; \geq 30 \mathrm{~kg} / \mathrm{m}^{2}$, $n=674)$. Other than weight and BMI, there were some differences between baseline characteristics when analyzed by baseline BMI, including a higher proportion of male participants in the $25 \mathrm{~kg} / \mathrm{m}^{2}-<30 \mathrm{~kg} / \mathrm{m}^{2}$ category than the $<25 \mathrm{~kg} / \mathrm{m}^{2}$ category and a higher proportion of never-smokers in the $<25 \mathrm{~kg} / \mathrm{m}^{2}$ category than the $\geq 30$ $\mathrm{kg} / \mathrm{m}^{2}$ category. The proportion of patients using supplemental oxygen increased, while 6MWD decreased, with increasing BMI category (Table 1 ).

A total of 623 patients from the pirfenidone arms of ASCEND and CAPACITY were included in the additional analysis population and had a mean (standard deviation) baseline BMI of $29.87(4.43) \mathrm{kg} / \mathrm{m}^{2}$ (baseline BMI: $<25 \mathrm{~kg} / \mathrm{m}^{2}, n=73 ; 25 \mathrm{~kg} / \mathrm{m}^{2}-<30 \mathrm{~kg} / \mathrm{m}^{2}, n=265 ; \geq 30 \mathrm{~kg} /$ $\left.\mathrm{m}^{2}, n=285\right)$. There were differences between baseline characteristics when analyzed by baseline BMI, such as a higher proportion of males in the $25 \mathrm{~kg} / \mathrm{m}^{2}-<30 \mathrm{~kg} / \mathrm{m}^{2}$ and $\geq 30 \mathrm{~kg} / \mathrm{m}^{2}$ categories than the $<25 \mathrm{~kg} / \mathrm{m}^{2}$ category, a higher proportion of never-smokers in the $<25 \mathrm{~kg} / \mathrm{m}^{2}$ category than the $25 \mathrm{~kg} / \mathrm{m}^{2}-<30 \mathrm{~kg} / \mathrm{m}^{2}$ and $\geq 30 \mathrm{~kg} / \mathrm{m}^{2}$ categories, and a reduced $6 \mathrm{MWD}$ in the $\geq 30 \mathrm{~kg} / \mathrm{m}^{2}$ category compared with the $<25 \mathrm{~kg} / \mathrm{m}^{2}$ and $25 \mathrm{~kg} / \mathrm{m}^{2}-<30 \mathrm{~kg} / \mathrm{m}^{2}$ categories. The proportion of patients using supplemental oxygen at baseline and SGRQ score at baseline increased with increasing BMI category (see online suppl. Table 1; see www.karger.com/doi/10.1159/000518855 for all online suppl. material).

\section{Clinical Outcomes up to 1 Year Post-Randomization \\ Stratified by Baseline BMI in Patients from the \\ Placebo Arms of ASCEND and CAPACITY, and All \\ Patients from INSPIRE and RIFF (Cohort A)}

A total of 1,604 patients from the placebo arms of ASCEND and CAPACITY and both treatment arms of INSPIRE and RIFF (Cohort A) were included in this analysis (baseline BMI: $<25 \mathrm{~kg} / \mathrm{m}^{2}, n=227 ; 25 \mathrm{~kg} / \mathrm{m}^{2}-<30 \mathrm{~kg} / \mathrm{m}^{2}$, $n=703 ; \geq 30 \mathrm{~kg} / \mathrm{m}^{2}, n=674$ ). The proportion of patients with a relative decline of $\geq 10 \%$ in percent predicted FVC or death up to 1 year post-randomization was highest in patients with a baseline BMI $<25 \mathrm{~kg} / \mathrm{m}^{2}$ (estimate, $19.0 \%$ $[95 \%$ CI 12.7, 25.4]) and lowest in those with BMI $\geq 30 \mathrm{~kg} /$ $\mathrm{m}^{2}$ (estimate, 9.4\% [95\% CI 4.8, 14.1]; shown in Fig. 1a [observed data]; shown in Table 2 [model estimates]).

Patients with a baseline BMI $<25 \mathrm{~kg} / \mathrm{m}^{2}$ had a greater estimated annualized decline in percent predicted FVC than patients with a baseline BMI $25 \mathrm{~kg} / \mathrm{m}^{2}-<30 \mathrm{~kg} / \mathrm{m}^{2}$ or baseline BMI $\geq 30 \mathrm{~kg} / \mathrm{m}^{2}$ (Table 2). Patients with a baseline BMI $<25 \mathrm{~kg} / \mathrm{m}^{2}$ also had greater estimated annualized worsening of percent predicted DLco and SGRQ total score than patients with a baseline BMI $\geq 30 \mathrm{~kg} / \mathrm{m}^{2}$ (Table 2). Furthermore, an estimated annualized 6MWD decline was numerically greater in patients with a baseline BMI $<25 \mathrm{~kg} / \mathrm{m}^{2}$ versus $25 \mathrm{~kg} / \mathrm{m}^{2}-<30 \mathrm{~kg} / \mathrm{m}^{2}$ and $\geq 30 \mathrm{~kg} /$ $\mathrm{m}^{2}$. Estimated all-cause hospitalization and mortality 
Table 1. Demographic and baseline characteristics by baseline BMI category

\begin{tabular}{|c|c|c|c|}
\hline \multirow[t]{2}{*}{ Demographic/characteristic* } & \multicolumn{3}{|l|}{ Baseline BMI } \\
\hline & $\begin{array}{l}<25 \mathrm{~kg} / \mathrm{m}^{2} \\
(n=227)\end{array}$ & $\begin{array}{l}25-<30 \mathrm{~kg} / \mathrm{m}^{2} \\
(n=703)\end{array}$ & $\begin{array}{l}\geq 30 \mathrm{~kg} / \mathrm{m}^{2} \\
(n=674)\end{array}$ \\
\hline Age at randomization, years & $68.3(7.5)$ & $67.9(7.6)$ & $65.2(7.6)$ \\
\hline Male, $n(\%)$ & $142(62.6)$ & $552(78.5)$ & $484(71.8)$ \\
\hline White, $n(\%)$ & $185(81.5)$ & $620(88.8)$ & $612(91.1)$ \\
\hline \multicolumn{4}{|l|}{ Weight at baseline, $\mathrm{kg}$} \\
\hline Male & $70.5(7.6)$ & $83.4(8.7)$ & $102.5(13.3)$ \\
\hline Female & $59.3(6.4)$ & $69.8(7.3)$ & $89.0(12.7)$ \\
\hline \multicolumn{4}{|l|}{$\mathrm{BMI}$ at baseline } \\
\hline Male & $23.5(1.2)$ & $27.7(1.4)$ & $33.6(3.2)$ \\
\hline Female & $22.9(1.7)$ & $27.6(1.4)$ & $34.9(4.5)$ \\
\hline \multicolumn{4}{|l|}{ HRCT diagnosis group at baseline, $n(\%)$} \\
\hline Definite UIP & $212(93.4)$ & $643(91.5)$ & $590(87.7)$ \\
\hline Probable/possible UIP & $15(6.6)$ & $60(8.5)$ & $83(12.3)$ \\
\hline Uncertain with UIP & $0(0)$ & $0(0)$ & $0(0)$ \\
\hline Time from IPF diagnosis to randomization, years & $1.4(1.2)$ & $1.2(1.1)$ & $1.1(1.0)$ \\
\hline Percent predicted FVC & $73.3(13.3)$ & $72.1(13.5)$ & $72.1(13.0)$ \\
\hline $\mathrm{FEV}_{1} / \mathrm{FVC}$ ratio & $0.8(0.1)$ & $0.8(0.1)$ & $0.8(0.1)$ \\
\hline Percent predicted DLco & $45.3(10.2)$ & $45.5(10.9)$ & $47.2(9.6)$ \\
\hline Baseline 6MWD, $\mathrm{m}$ & $434.5(111.4)$ & $414.2(109.8)$ & $389.5(105.7)$ \\
\hline Baseline SGRQ score $^{\dagger}$ & $38.8(17.6)^{\dagger}$ & $37.5(18.0)^{\ddagger}$ & $43.9(17.3)^{\S}$ \\
\hline Supplemental oxygen use at baseline, $n(\%)$ & $20(8.8)$ & $106(15.1)$ & $160(23.8)$ \\
\hline \multicolumn{4}{|l|}{ Smoking status at screening, $n(\%)$} \\
\hline Current & $7(3.1)$ & $21(3.0)$ & $25(3.7)$ \\
\hline History & $131(57.7)$ & $442(62.9)$ & $475(70.5)$ \\
\hline Never & $89(39.2)$ & $240(34.1)$ & $174(25.8)$ \\
\hline
\end{tabular}

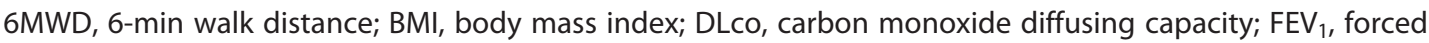
expiratory volume in 1 second; FVC, forced vital capacity; HRCT, high-resolution computed tomography; IPF, idiopathic pulmonary fibrosis; SD, standard deviation; SGRQ, St. George's Respiratory Questionnaire; UIP, usual interstitial pneumonia. *Data are presented as mean (SD) unless specified otherwise. ${ }^{\dagger} n=165 .{ }^{\ddagger} n=537 .{ }^{\S} n=526$.

rates, and the proportion of patients experiencing an SAE up to 1 year, were similar across the subgroups stratified by baseline BMI (Table 2).

\section{Clinical Outcomes up to 1 Year Post-Randomization Stratified by Annualized Percent Change in Body Weight in Patients from the Placebo Arms of ASCEND and CAPACITY, and All Patients from INSPIRE and RIFF (Cohort A)}

In total, 1,558 patients from the placebo arms of ASCEND and CAPACITY and both treatment arms of INSPIRE and RIFF (Cohort A) were included in this analysis (no weight loss, $n=849$; $>0-<5 \%$ loss, $n=610$; $\geq 5 \%$ loss, $n=99$ [21 [21.2\%] patients who experienced $\geq 5 \%$ loss also had a baseline BMI $\left.<25 \mathrm{~kg} / \mathrm{m}^{2}\right]$ ).

Patients with no weight loss experienced the lowest rate of $\geq 10 \%$ relative decline in percent predicted $\mathrm{FVC}$ or death up to 1 year post-randomization (estimate, 9.5\% [95\% CI 5.0, 14.1]; shown in Fig. 1b [observed data]; Table 3 [model estimates]). Patients who experienced no weight loss also had reduced estimated annualized worsening of percent predicted FVC, percent predicted DLco, $6 \mathrm{MWD}$, and SGRQ total score compared with those who experienced a $>0-<5 \%$ loss or a $\geq 5 \%$ loss (Table 3 ).

Compared with patients who experienced no weight loss, a greater percentage of patients with a $>0-<5 \%$ loss or a $\geq 5 \%$ loss were hospitalized in 1 year, and mortality was numerically higher in patients with weight loss versus those without weight loss (Table 3). Patients with a $\geq 5 \%$ weight loss were also more likely to experience any SAE during the study than those with no weight loss.

Results from the sensitivity analysis that excluded 19 patients with no post-baseline body weight measurement after day 90 (online suppl. Table 2) were consistent with 
Fig. 1. Proportion of patients from the placebo arms of ASCEND and CAPACITY and all patients from INSPIRE and RIFF (Cohort A) with an absolute or relative decline of $\geq 10 \%$ in percent predicted FVC or death up to 1 year post-randomization, stratified by baseline BMI category (a) and annualized percent change in body weight category (b). BMI, body mass index; FVC, forced vital capacity.

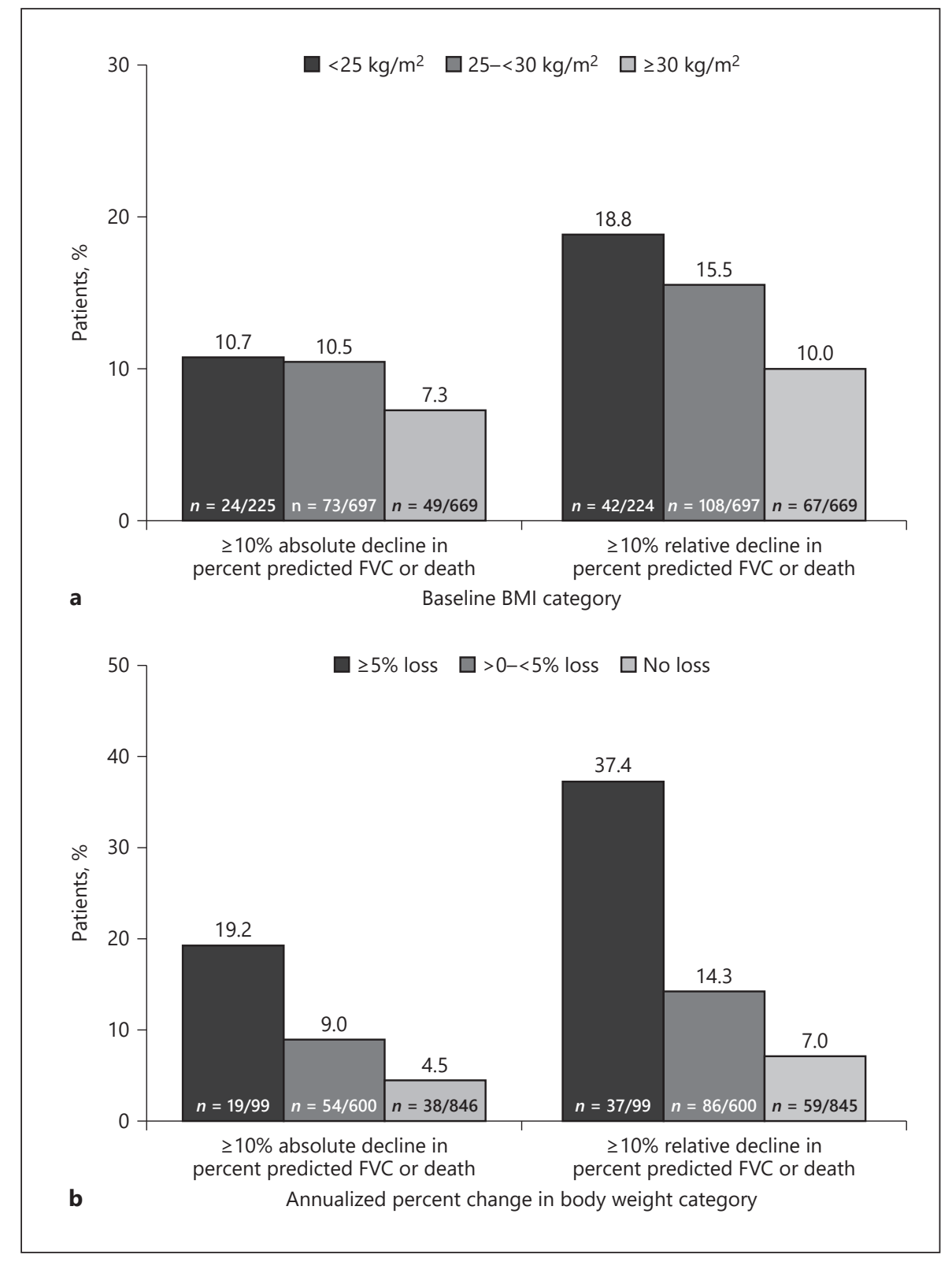

those seen in the main analysis (Table 3). In time-to-event analyses, patients with no weight loss had a significantly lower risk of experiencing a first incidence of all-cause hospitalization or experiencing all-cause mortality over 1 year than patients with a $>0-<5 \%$ loss or a $\geq 5 \%$ loss (shown in Fig. 2, 3, respectively). Results from the sensitivity analysis of time to first all-cause hospitalization, which treated any death that occurred without a prior hospitalization as a competing risk event, were consistent with the main analysis (online suppl. Fig. 1).
Clinical Outcomes up to 1 Year Post-Randomization Stratified by Baseline BMI and Annualized Percent Change in Body Weight in Patients from the Pirfenidone Treatment Arms of ASCEND and CAPACITY

In total, 623 pirfenidone-treated patients from ASCEND and CAPACITY were included in this analysis (baseline BMI: $<25 \mathrm{~kg} / \mathrm{m}^{2}, n=73 ; 25 \mathrm{~kg} / \mathrm{m}^{2}-<30 \mathrm{~kg} / \mathrm{m}^{2}$, $n=265 ; \geq 30 \mathrm{~kg} / \mathrm{m}^{2}, n=285$; annualized percent change in body weight: no weight loss, $n=374$; $>0-<5 \%$ loss, $n=165$; $\geq 5 \%$ loss, $n=84$ ). In pirfenidone-treated pa- 
Table 2. Clinical outcomes at 1 year, stratified by baseline BMI category, in patients from the placebo arms of ASCEND and CAPACITY and all patients from INSPIRE and RIFF (Cohort A)

\begin{tabular}{|c|c|c|c|}
\hline \multirow[t]{2}{*}{ Outcome } & \multicolumn{3}{|l|}{ Baseline BMI } \\
\hline & $\begin{array}{l}<25 \mathrm{~kg} / \mathrm{m}^{2} \\
(n=227)\end{array}$ & $\begin{array}{l}25-<30 \mathrm{~kg} / \mathrm{m}^{2} \\
(n=703)\end{array}$ & $\begin{array}{l}\geq 30 \mathrm{~kg} / \mathrm{m}^{2} \\
(n=674)\end{array}$ \\
\hline \multicolumn{4}{|c|}{ Annualized change from baseline in percent predicted FVC, \%* } \\
\hline Observed, $n$ & 225 & 697 & 669 \\
\hline Estimate $(95 \% \mathrm{Cl})$ & $-6.6(-7.5$ to -5.8$)$ & $-5.4(-5.9$ to -5.0$)$ & $-4.1(-4.6$ to -3.7$)$ \\
\hline Difference $(95 \% \mathrm{Cl})^{\dagger}$ & & $1.2(0.2,2.2)$ & $2.5(1.5,3.5)$ \\
\hline \multicolumn{4}{|c|}{ Annualized change from baseline in percent predicted DLco, $\%^{*, \neq}$} \\
\hline Observed, $n$ & 180 & 575 & 559 \\
\hline Estimate $(95 \% \mathrm{Cl})$ & $-5.5(-6.4$ to -4.5$)$ & $-5.0(-5.5$ to -4.5$)$ & $-4.0(-4.5$ to -3.5$)$ \\
\hline Difference $(95 \% \mathrm{Cl})^{\dagger}$ & & $0.4(-0.6$ to 1.5$)$ & $1.5(0.4,2.5)$ \\
\hline \multicolumn{4}{|c|}{ Annualized change from baseline in 6MWD, $\mathrm{m}^{*}$} \\
\hline Observed, $n$ & 225 & 698 & 669 \\
\hline Estimate $(95 \% \mathrm{Cl})$ & $-42.8(-53.8$ to -31.9$)$ & $-32.5(-38.6$ to -26.4$)$ & $-30.5(-36.7$ to -24.3$)$ \\
\hline Difference $(95 \% \mathrm{Cl})^{\dagger}$ & & $10.3(-2.2$ to 22.8$)$ & $12.3(-0.2$ to 24.9$)$ \\
\hline \multicolumn{4}{|c|}{ Annualized change from baseline in SGRQ total score*, } \\
\hline Observed, $n$ & 178 & 575 & 558 \\
\hline Estimate $(95 \% \mathrm{Cl})$ & $5.8(4.3,7.2)$ & $5.2(4.4,6.0)$ & $3.1(2.3,4.0)$ \\
\hline Difference $(95 \% \mathrm{Cl})^{\dagger}$ & & $-0.6(-2.2$ to 1.1$)$ & $-2.6(-4.3$ to -1.0$)$ \\
\hline \multicolumn{4}{|c|}{ Absolute decline in percent predicted FVC $\geq 10 \%$ or death up to 1 year post-randomization, $\%^{\S}$} \\
\hline Observed, $n$ & 225 & 697 & 669 \\
\hline Estimate $(95 \% \mathrm{Cl})$ & $11.0(5.8,16.2)$ & $10.1(6.1,14.1)$ & $7.0(3.2,10.8)$ \\
\hline Difference $(95 \% \mathrm{Cl})^{\dagger}$ & & $-0.9(-5.7$ to 3.8$)$ & $-4.0(-8.8$ to 0.7$)$ \\
\hline \multicolumn{4}{|c|}{ Relative decline in percent predicted FVC $\geq 10 \%$ or death up to 1 year post-randomization, $\% \S$} \\
\hline Observed, $n$ & 224 & 697 & 669 \\
\hline Estimate $(95 \% \mathrm{Cl})$ & $19.0(12.7,25.4)$ & $15.1(10.4,19.8)$ & $9.4(4.8,14.1)$ \\
\hline Difference $(95 \% \mathrm{Cl})^{\dagger}$ & & $-3.9(-9.8$ to 1.9$)$ & $-9.6(-15.4$ to -3.8$)$ \\
\hline \multicolumn{4}{|c|}{ Any all-cause hospitalization up to 1 year post-randomization, $\% \S$} \\
\hline Observed, $n$ & 225 & 698 & 669 \\
\hline Estimate $(95 \% \mathrm{Cl})$ & $23.8(16.6,30.9)$ & $25.4(19.7,31.1)$ & $24.5(19.2,29.9)$ \\
\hline Difference $(95 \% \mathrm{Cl})^{\dagger}$ & & $1.7(-4.3$ to 7.6$)$ & $0.8(-5.4$ to 7.0$)$ \\
\hline \multicolumn{4}{|c|}{ All-cause mortality up to 1 year post-randomization, $\% \S$} \\
\hline Observed, $n$ & 225 & 698 & 669 \\
\hline Estimate $(95 \% \mathrm{Cl})$ & $6.7(2.0,11.5)$ & $7.9(4.3,11.6)$ & $6.2(2.8,9.6)$ \\
\hline Difference $(95 \% \mathrm{Cl})^{\dagger}$ & & $1.2(-2.5$ to 4.9$)$ & $-0.5(-4.2$ to 3.2$)$ \\
\hline \multicolumn{4}{|c|}{ Any treatment-emergent SAEs up to 1 year post-randomization, $\%^{\S}$} \\
\hline Observed, $n$ & 225 & 698 & 669 \\
\hline Estimate $(95 \% \mathrm{Cl})$ & $26.7(19.2,34.2)$ & $30.6(24.5,36.7)$ & $27.0(21.4,32.6)$ \\
\hline Difference $(95 \% \mathrm{Cl})^{\dagger}$ & & $3.9(-2.5$ to 10.3$)$ & $0.3(-6.3$ to 6.9$)$ \\
\hline
\end{tabular}

6MWD, 6-min walk distance; BMI, body mass index; Cl, confidence interval; DLco, carbon monoxide diffusing capacity; FVC, forced vital capacity; HRCT, high-resolution computed tomography; IPF, idiopathic pulmonary fibrosis; SAE, serious adverse event; SGRQ, St. George's Respiratory Questionnaire. * Estimates (95\% CI) based on repeated-measures analysis of covariance with study, age, sex, race, baseline HRCT status, years since IPF diagnosis, baseline oxygen use, baseline smoking status, baseline BMI category, time, and baseline BMI category*time as fixed-effect covariates, with random intercept and random slope for time for each patient. ${ }^{\dagger}$ Estimated difference from first category. ${ }^{\ddagger}$ Excludes ASCEND, study. ${ }^{\S}$ Estimates $(95 \% \mathrm{Cl})$ based on logistic regression with study, age, sex, race, baseline HRCT status, years since IPF diagnosis, baseline oxygen use, baseline smoking status, and baseline BMl category as model factors.

tients, the proportion of patients with a relative decline of $\geq 10 \%$ in percent predicted FVC or death up to 1 year post-randomization, and the annualized change in percent predicted FVC, percent predicted DLco, and $6 \mathrm{MWD}$, were generally similar across subgroups strati- fied by baseline BMI (online suppl. Table 3). Estimated all-cause hospitalization and mortality rates, and the proportion of patients who experienced an SAE up to 1 year post-randomization, were also similar across subgroups stratified by baseline BMI. However, patients 
Table 3. Clinical outcomes at 1 year, stratified by an annualized percent change in body weight, in patients from the placebo arms of ASCEND and CAPACITY and all patients from INSPIRE and RIFF (Cohort A)

\begin{tabular}{|c|c|c|c|}
\hline \multirow[t]{2}{*}{ Outcome } & \multicolumn{3}{|c|}{ Annualized percent change in body weight } \\
\hline & $\begin{array}{l}\text { No weight loss } \\
(n=849)\end{array}$ & $\begin{array}{l}>0-<5 \% \text { loss } \\
(n=610)\end{array}$ & $\begin{array}{l}\geq 5 \% \text { loss } \\
(n=99)\end{array}$ \\
\hline \multicolumn{4}{|c|}{ Annualized change from baseline in percent predicted FVC, \%* } \\
\hline Observed, $n$ & 846 & 600 & 99 \\
\hline Estimate $(95 \% \mathrm{Cl})$ & $-4.2(-4.7$ to -3.8$)$ & $-5.5(-6.0$ to -5.0$)$ & $-9.5(-10.7$ to -8.2$)$ \\
\hline Difference $(95 \% \mathrm{Cl})^{\dagger}$ & & $-1.3(-2.0$ to -0.7$)$ & $-5.2(-6.6$ to -3.9$)$ \\
\hline \multicolumn{4}{|c|}{ Annualized change from baseline in percent predicted DLco, \%*, } \\
\hline Observed, $n$ & 706 & 496 & 67 \\
\hline Estimate $(95 \% \mathrm{Cl})$ & $-4.1(-4.6$ to -3.7$)$ & $-5.2(-5.7$ to -4.6$)$ & $-6.9(-8.5$ to -5.3$)$ \\
\hline Difference $(95 \% \mathrm{Cl})^{\dagger}$ & & $-1.0(-1.7$ to -0.3$)$ & $-2.8(-4.4$ to -1.1$)$ \\
\hline \multicolumn{4}{|c|}{ Annualized change from baseline in 6MWD, $\mathrm{m}^{*}$} \\
\hline Observed, $n$ & 847 & 600 & 99 \\
\hline Estimate $(95 \% \mathrm{Cl})$ & $-25.6(-31.0$ to -20.3$)$ & $-37.2(-43.7$ to -30.7$)$ & $-81.1(-98.6$ to -63.5$)$ \\
\hline Difference $(95 \% \mathrm{CI})^{\dagger}$ & & $-11.6(-20.0$ to -3.2$)$ & $-55.5(-73.8$ to -37.1$)$ \\
\hline \multicolumn{4}{|c|}{ Annualized change from baseline in SGRQ total score*, } \\
\hline Observed, $n$ & 706 & 494 & 67 \\
\hline Estimate $(95 \% \mathrm{Cl})$ & $3.5(2.8,4.2)$ & $5.0(4.2,5.9)$ & $9.6(7.2,12.0)$ \\
\hline Difference $(95 \% \mathrm{Cl})^{\dagger}$ & & $1.5(0.4,2.6)$ & $6.1(3.6,8.6)$ \\
\hline \multicolumn{4}{|c|}{ Absolute decline in percent predicted FVC $\geq 10 \%$ or death up to 1 year post-randomization, $\% \S$} \\
\hline Observed, $n$ & 846 & 600 & 99 \\
\hline Estimate $(95 \% \mathrm{Cl})$ & $7.6(3.8,11.4)$ & $12.2(7.7,16.8)$ & $21.7(13.1,30.3)$ \\
\hline Difference $(95 \% \mathrm{Cl})^{\dagger}$ & & $4.6(1.4,7.9)$ & $14.1(5.7,22.5)$ \\
\hline \multicolumn{4}{|c|}{ Relative decline in percent predicted FVC $\geq 10 \%$ or death up to 1 year post-randomization, $\%^{\S}$} \\
\hline Observed, $n$ & 845 & 600 & 99 \\
\hline Estimate $(95 \% \mathrm{Cl})$ & $9.5(5.0,14.1)$ & $16.8(11.6,22.0)$ & $38.0(27.7,48.3)$ \\
\hline Difference $(95 \% \mathrm{Cl})^{\dagger}$ & & $7.3(3.6,11.0)$ & $28.4(18.5,38.3)$ \\
\hline \multicolumn{4}{|c|}{ Any all-cause hospitalization up to 1 year post-randomization, $\%^{\S}$} \\
\hline Observed, $n$ & 847 & 600 & 99 \\
\hline Estimate $(95 \% \mathrm{Cl})$ & $20.4(15.2,25.7)$ & $26.2(20.5,32.0)$ & $40.6(30.3,50.9)$ \\
\hline Difference $(95 \% \mathrm{CI})^{\dagger}$ & & $5.8(1.8,9.9)$ & $20.2(10.3,30.0)$ \\
\hline \multicolumn{4}{|c|}{ All-cause mortality up to 1 year post-randomization, $\% \S$} \\
\hline Observed, $n$ & 847 & 600 & 99 \\
\hline Estimate $(95 \% \mathrm{Cl})$ & $7.6(3.7,11.5)$ & $10.6(5.6,15.6)$ & $11.7(3.7,19.7)$ \\
\hline Difference $(95 \% \mathrm{Cl})^{\dagger}$ & & $3.0(-0.6$ to 6.7$)$ & $4.1(-3.4$ to 11.6$)$ \\
\hline \multicolumn{4}{|c|}{ Any treatment-emergent SAEs up to 1 year post-randomization, $\%^{\S}$} \\
\hline Observed, $n$ & 847 & 600 & 99 \\
\hline Estimate $(95 \% \mathrm{Cl})$ & $23.3(17.8,28.8)$ & $27.3(21.3,33.2)$ & $52.0(41.3,62.7)$ \\
\hline Difference $(95 \% \mathrm{Cl})^{\dagger}$ & & $4.0(-0.3,8.2)$ & $28.7(18.4,39.0)$ \\
\hline
\end{tabular}

6MWD, 6-min walk distance; $\mathrm{Cl}$, confidence interval; DLco, carbon monoxide diffusing capacity; FVC, forced vital capacity; HRCT, high-resolution computed tomography; IPF, idiopathic pulmonary fibrosis; SAE, serious adverse event; SGRQ, St. George's Respiratory Questionnaire. * Estimates $(95 \% \mathrm{Cl})$ based on repeated-measures analysis of covariance with study, age, sex, race, baseline HRCT status, years since IPF diagnosis, baseline oxygen use, baseline smoking status, annualized percent change category, time, and annualized percent change category*time as fixedeffect covariates, with random intercept and random slope for time for each patient. ${ }^{\dagger}$ Estimated difference from first category. ${ }^{\ddagger}$ Excludes ASCEND study. ${ }^{\S}$ Estimates $(95 \% \mathrm{Cl}$ ) based on logistic regression with study, age, sex, race, baseline HRCT status, years since IPF diagnosis, baseline oxygen use, baseline smoking status, and annualized percent change in body weight category as model factors.

with a baseline BMI $<25 \mathrm{~kg} / \mathrm{m}^{2}$ experienced an improvement in SGRQ total score, whereas patients with a baseline BMI $25 \mathrm{~kg} / \mathrm{m}^{2}-<30 \mathrm{~kg} / \mathrm{m}^{2}$ or a baseline BMI $\geq 30 \mathrm{~kg} /$ $\mathrm{m}^{2}$ experienced a worsening of SGRQ total score (online suppl. Table 3).
When stratified by annualized percent change in body weight, patients with no weight loss experienced a lower rate of $\geq 10 \%$ absolute or relative decline in percent predicted FVC or death up to 1 year post-randomization than those who experienced $a \geq 5 \%$ loss (online suppl. Ta- 


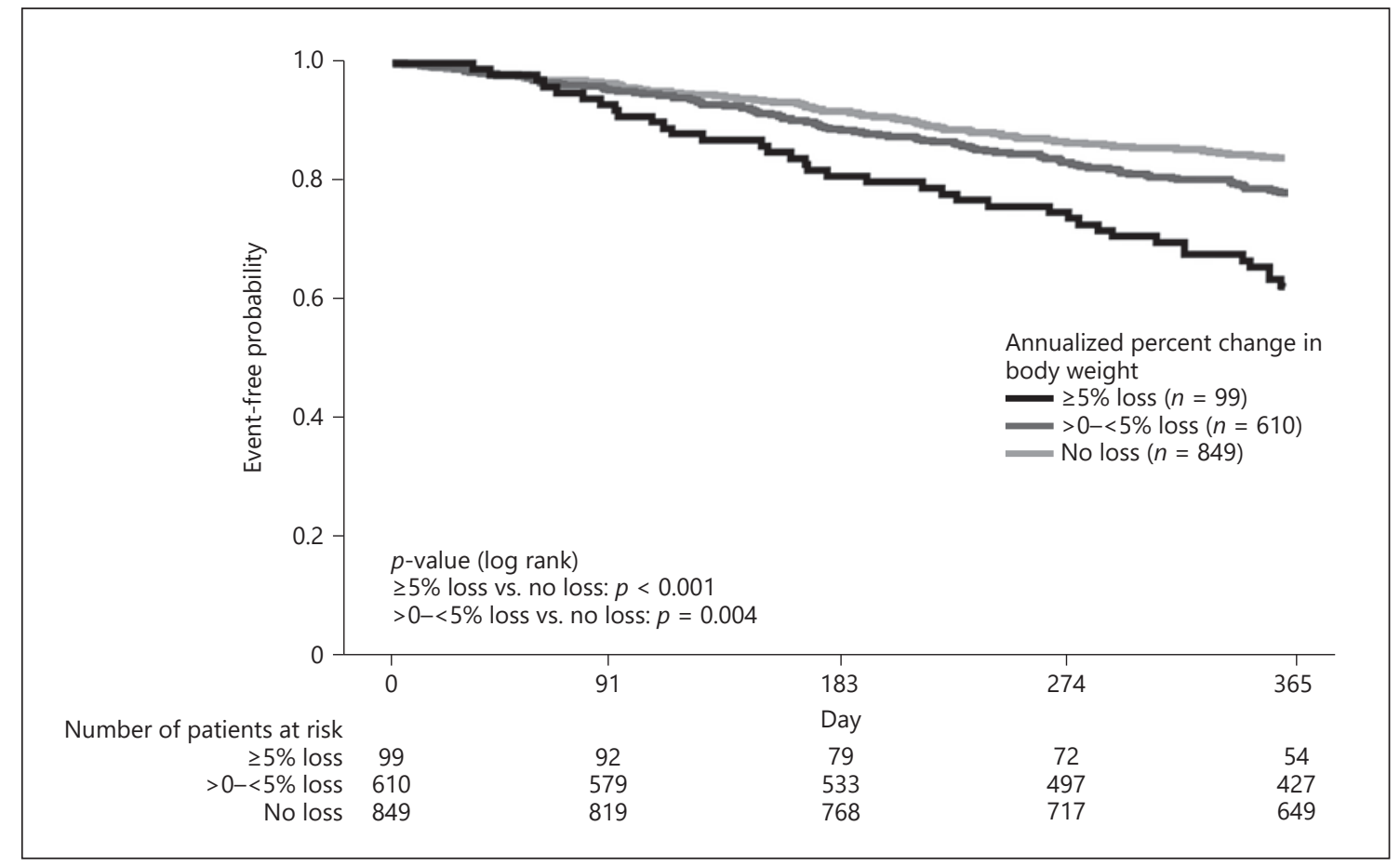

Fig. 2. Time-to-event analysis of first all-cause hospitalization up to 1 year post-randomization, stratified by an annualized percent change in body weight categories, in patients from the placebo arms of ASCEND and CAPACITY and all patients from INSPIRE and RIFF (Cohort A).

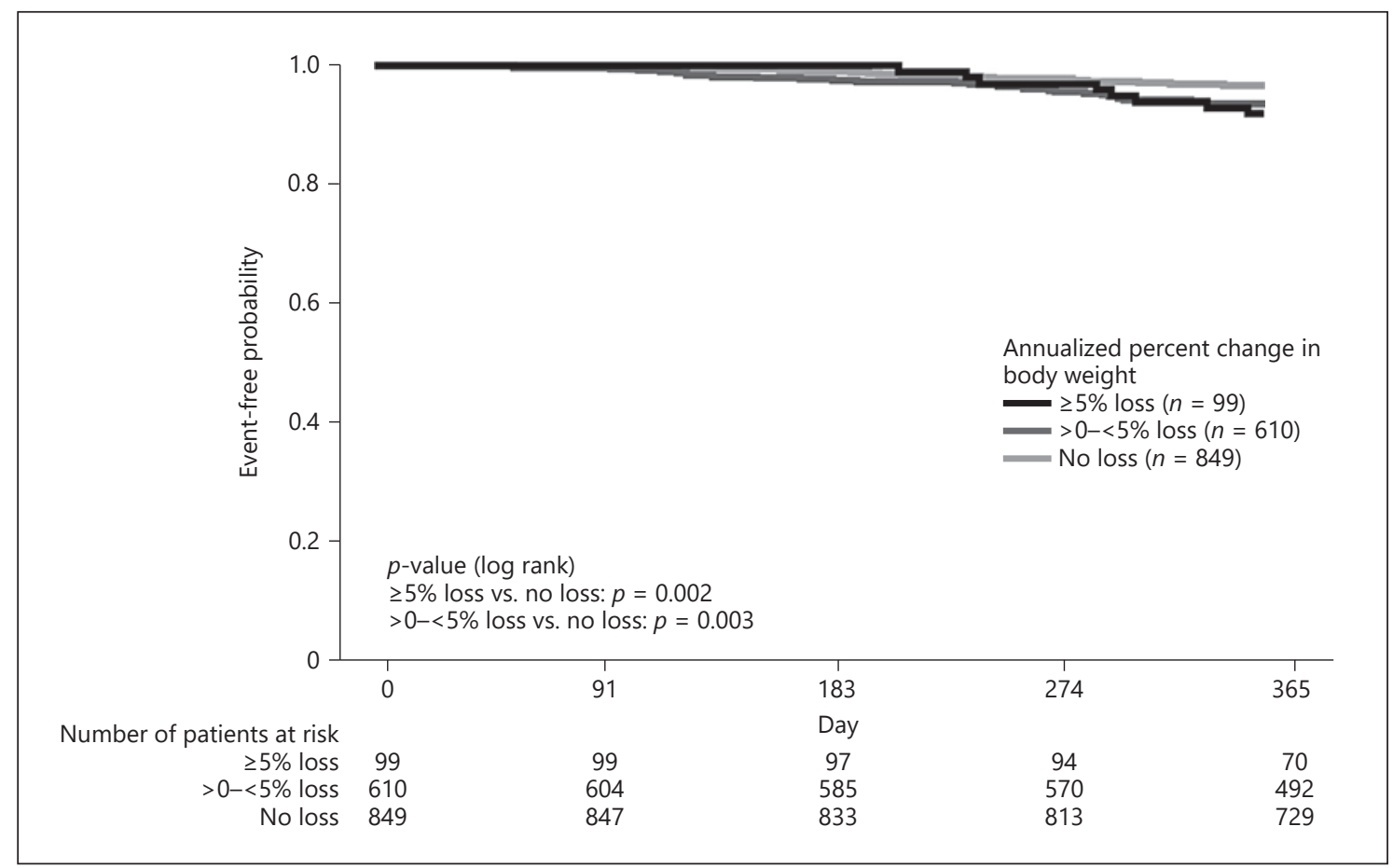

Fig. 3. Time-to-event analysis of all-cause mortality up to 1 year post-randomization, stratified by an annualized percent change in body weight categories, in patients from the placebo arms of ASCEND and CAPACITY, and all patients from INSPIRE and RIFF (Cohort A). 
ble 4 [model estimates]). When compared with patients who experienced $\mathrm{a} \geq 5 \%$ loss, patients who experienced no weight loss had reduced estimated worsening of percent predicted FVC, percent predicted DLco, 6MWD, and SGRQ total score, and lower estimated rates of any allcause hospitalization and any SAE up to 1 year post-randomization. Patients who experienced no weight loss also had numerically lower rates of all-cause mortality compared with those who experienced $a \geq 5 \%$ loss (online suppl. Table 4).

In time-to-event analyses, patients who experienced no weight loss had a lower risk of experiencing a first incidence of all-cause hospitalization over 1 year than patients who experienced a $>0-<5 \%$ loss or a $\geq 5 \%$ loss ( $p<$ 0.01 and $p<0.001$, respectively). Patients who experienced no weight loss also had a significantly lower risk of experiencing all-cause mortality over 1 year than patients who experienced a $\geq 5 \%$ loss $(p<0.05)$.

\section{Discussion}

The results of the pooled post hoc analysis including patients from the placebo arms of ASCEND and CAPACITY, and all patients from INSPIRE and RIFF (Cohort A), suggest that patients with IPF who have a baseline BMI $<25 \mathrm{~kg} / \mathrm{m}^{2}$ or who lose weight in 1 year may experience worse clinical outcomes up to 1 year than those with a baseline BMI $\geq 25 \mathrm{~kg} / \mathrm{m}^{2}$ or those who experience no weight loss. No significant relationships were observed between baseline BMI and the incidence of hospitalization, mortality, or SAEs; however, a greater percentage of patients with weight loss experienced all-cause hospitalization versus patients with no weight loss, and a greater percentage of patients with $\geq 5 \%$ loss experienced an SAE versus patients with no weight loss. Interestingly, in timeto-event analyses, patients with no weight loss had a significantly lower risk of first incidence of all-cause hospitalization and all-cause mortality up to 1 year post-randomization than patients with weight loss, and results from the sensitivity analysis were consistent with the hospitalization finding.

The results of the post hoc analysis including patients from the pirfenidone arms of ASCEND and CAPACITY highlight that outcomes were similar across all subgroups stratified by baseline BMI, with the exception of patients with a baseline BMI $<25 \mathrm{~kg} / \mathrm{m}^{2}$, who experienced an improvement in SGRQ total score, whereas patients with a baseline BMI $25 \mathrm{~kg} / \mathrm{m}^{2}-<30 \mathrm{~kg} / \mathrm{m}^{2}$ or $\geq 30 \mathrm{~kg} / \mathrm{m}^{2}$ experienced a worsening of SGRQ total score. Patients in this analysis with $\geq 5 \%$ weight loss experienced worse clinical outcomes up to 1 year than patients with no weight loss. Furthermore, patients in this analysis who experienced no weight loss had lower estimated rates of all-cause hospitalization and SAEs up to 1 year post-randomization versus patients who experienced a $\geq 5 \%$ weight loss, and had numerically lower rates of all-cause mortality versus those who experienced a $\geq 5 \%$ weight loss. As each analysis population was comprised of different patient populations from several clinical trials, and the size of the placebo population was increased by combining all patients from INSPIRE and RIFF (Cohort A) with the placebo patients from ASCEND and CAPACITY, it is not possible to directly compare outcomes between analysis populations. However, generally, patients included in the placebo analysis population experienced worse outcomes than pirfenidone-treated patients across baseline BMI and annualized weight-change subgroups, with the exception of percent predicted DLco.

Our findings expand on results from other studies that have assessed the relationship between BMI, weight loss, and outcomes in IPF [12-14, 25-27]. A single-center cohort study that used bioelectrical impedance analysis found that BMI was independently associated with mortality in IPF [27], and US registry data identified a relationship between longitudinal reductions in $\mathrm{BMI}$ and risk of mortality [12]. A further study highlighted that weight loss and BMI are associated with increased risk of mortality in patients with IPF, with weight loss being regarded as a longitudinal marker of disease progression [14]. In a multicenter cohort study of patients from the UK and Japan, patients who experienced $>5 \%$ weight loss experienced increased FVC decline over 1 year and had worse survival rates versus patients with no weight loss, similar to the results observed in our post hoc analysis [13]. Additionally, in line with the results from our post hoc analysis, post hoc analyses of data from the INPULSIS trials of nintedanib identified that the rate of SAEs was similar between BMI subgroups [25]. Interestingly, the rate of mortality was numerically greater in patients with BMI $<25 \mathrm{mg} / \mathrm{kg}^{2}$ versus $\mathrm{BMI} \geq 25 \mathrm{mg} / \mathrm{kg}^{2}$ [25]. Moreover, the rate of SAEs over 52 weeks was also numerically greater in placebo-treated patients with $>5 \%$ weight loss versus $\leq 5 \%$ weight loss [25], similar to the results of our post hoc analysis. However, in contrast to our findings and the findings from a real-world registry [26], the rate of mortality in the INPULSIS studies was numerically lower in placebo-treated patients with $>5 \%$ weight loss versus $\leq 5 \%$ weight loss [25]. 
Furthermore, post hoc analyses of data from the INPULSIS trials identified that the rate of FVC decline (mL/ year) and worsening of SGRQ scores over 52 weeks were numerically greater in placebo-treated patients with BMI $<25 \mathrm{mg} / \mathrm{kg}^{2}$ versus patients with $\mathrm{BMI} \geq 25 \mathrm{mg} / \mathrm{kg}^{2}$ [25]. Moreover, in the INPULSIS studies, the rate of FVC decline (mL/year) and worsening of SGRQ scores over 52 weeks were numerically greater in placebo-treated patients with $>5 \%$ weight loss versus $\leq 5 \%$ weight loss [25], similar to the results of our post hoc analysis. The results from our post hoc analysis and the results from previous studies suggest that a BMI of $<25 \mathrm{~kg} / \mathrm{m}^{2}$ and weight loss may be associated with worse clinical outcomes in patients with IPF [12-14, 25-27].

Reduced appetite and weight loss are frequently reported as AEs in patients with IPF, including those treated with placebo. Post hoc analyses of data from the INPULSIS trials of nintedanib revealed that in patients in the placebo arm, the rate of decreased appetite was greater in patients who experienced a $>5 \%$ weight loss than in patients with a $\leq 5 \%$ weight loss [25]. However, it is difficult to generate an estimate of treatment effect on clinical outcomes in groups of patients stratified by weight loss. As weight-loss subgroups are defined by measurements taken after treatment initiation rather than at baseline, these measurements may be an intermediate result of treatment initiation and may lead to a biased estimate of treatment effect on other clinical outcomes. Furthermore, while treatment with antifibrotics can lead to weight-loss-related AEs and associated poor outcomes, patients may also experience a reduction in lung-function decline irrespective of weight loss, as shown in a post hoc analysis of the INPULSIS study [25].

It is important to look beyond appetite and weight loss and consider the complexities of disease-associated malnutrition. Reduced appetite may not necessarily lead to malnutrition if a patient does not reduce their food intake as a result; likewise, even when appetite is not reduced, patients may report decreased food intake due to factors such as nausea from the use of specific medications [28]. Furthermore, in a primary care setting, reduced food intake (regardless of cause) is thought to be correlated with the diagnosis of malnutrition and can easily be measured using the Simple Evaluation of Food Intake (SEFI ${ }^{\circledR}$; K'noë Groupe GET, le Kremlin Bicêtre, France) [29]. Additionally, as the disease progresses, symptoms such as breathlessness and cough worsen [30,31], and subsequently eating becomes more difficult for patients [32]. IPF itself may also be associated with changes in metabolism regulation (e.g., autophagy, oxidative stress, mitochondrial

Clinical Outcomes in IPF by BMI and Weight Loss dysfunction, and death-receptor-induced pathways, including tumor necrosis factor-alpha), which may also have an effect on muscle mass and function, general health status, IPF severity, and further weight loss [3336]. Levels of profibrotic mediators such as tumor necrosis factor-alpha are known to be increased in the fibrotic lung [36], and the role of these in influencing food intake is not clear.

From a broader perspective, it is clear that body weight and percentage loss should be measured regularly, and that clinicians should be alert to the criteria and risk factors for malnutrition. In patients with IPF, prospective studies involving repeated body composition measurements are needed in order to better understand the ways in which weight loss impacts on outcomes. Future studies in IPF should incorporate validated methods to assess body composition and muscle function to better understand the relationship between weight loss/BMI and poor outcomes. Low baseline BMI has been suggested as a predictor of poor antifibrotic tolerance [37]; however, this was not assessed in our post hoc analysis. Therefore, it may be of value for future studies to also investigate BMIadjusted doses of antifibrotics in patients with IPF. Furthermore, it may also be important for future studies to consider the association between pleuroparenchymal fibroelastosis, which can often be associated with or misdiagnosed as IPF or other forms of ILD, and weight loss [38].

Limitations of this analysis include that this was a post hoc analysis from studies that were not designed to assess the effects of BMI or weight loss on outcomes, nor was the type I error controlled for positive findings - prospective datasets are required to evaluate whether weight loss is independently associated with clinical outcomes. It is also important to note that the strict inclusion and exclusion criteria of the original clinical trials may have resulted in a patient population that is not entirely representative of clinical practice. Furthermore, although the annualized percentage weight change was similar between the active and placebo arms of INSPIRE and RIFF (Cohort A), the drug effects of interferon- $\gamma-1 b$ and lebrikizumab may also have played a role in body weight, appetite, and related endpoints [20,21]; however, the occurrence of gastrointestinal AEs such as diarrhea was similar across the placebo and treatment arms of INSPIRE and RIFF (Cohort A) $[20,21]$. Given that antifibrotic treatment can result in weight loss in patients with IPF [39], it is possible that pirfenidone may have influenced body weight in patients included in the pirfenidone analysis, thereby impacting the measured outcomes $[18,19]$. As this study 
only looked at outcomes over 1 year, further research is required to assess the impact of weight loss on outcomes over a longer time period.

A further limitation of this analysis is that because annualized weight loss was measured over the same 1-year period as the outcomes investigated and took into account all data available during this time period, it is not possible to determine if IPF is causative of weight loss and/or if other factors, such as SAEs, hospitalization, or declining functional status, need to be considered. Therefore, although factors associated with weight loss in IPF have been identified previously [39], further studies that assess weight loss prior to the outcome event are required. Additionally, because BMI and annualized weight loss were not analyzed as continuous variables, it is not possible to comment on whether a linear relationship exists between these predictors and the outcomes in this analysis. Categories of BMI were used, rather than BMI as a continuous variable, as these correspond to the definitions of normal weight, overweight, and obese. Moreover, it is thought that weight-loss categories may be more applicable in the clinic than weight loss as a continuous variable. Another limitation is that factors that may be associated with worse outcomes in patients with IPF, such as the presence of anxiety and depression, were unmeasured in this analysis. As this analysis only considered the relationship between outcomes and baseline BMI and annualized weight loss, we cannot comment on any causal relationship between disease-associated malnutrition and outcomes.

\section{Conclusions}

The results of this pooled post hoc analysis suggest that placebo-treated patients with a baseline BMI $<25 \mathrm{~kg} / \mathrm{m}^{2}$ or who lose $>0-<5 \%$ or $\geq 5 \%$ of their body weight in 1 year may experience worse clinical outcomes up to 1 year than those with a baseline BMI $25 \mathrm{~kg} / \mathrm{m}^{2}-<30 \mathrm{~kg} / \mathrm{m}^{2}$ (overweight) or $\geq 30 \mathrm{~kg} / \mathrm{m}^{2}$ (obese), or who experience no weight loss. Additionally, pirfenidone-treated patients who lose $\geq 5 \%$ of their body weight in 1 year may experience worse clinical outcomes than those who experience no weight loss. The clinical relevance of these findings warrants further research to increase the understanding of the relationship between body weight and individual clinical outcomes, and the relative importance of individual factors on overall prognosis. Future trials should aim to demonstrate whether dedicated management to prevent malnutrition and weight loss can improve clinical outcomes in patients with IPF.

\section{Acknowledgments}

Medical writing support was provided by Ceilidh McConnachie, MSc, of CMC AFFINITY, McCann Health Medical Communications, funded by Genentech, Inc. and F. Hoffmann-La Roche, Ltd.

\section{Statement of Ethics}

No prospective data were collected during this post hoc analysis; therefore, ethical approval was not required; however, during the original trials, all patients provided informed consent and the protocols were approved by the institutional review boards or ethics committees at each participating center.

\section{Conflict of Interest Statement}

S.J. has received fees, funding, or reimbursement for participation at meetings from Actelion, AIRB, AstraZeneca, Bellerophon Therapeutics, Biogen, Boehringer Ingelheim, Bristol-Myers Squibb, Chiesi, F. Hoffmann-La Roche, Ltd., Galecto Biotech, Gilead, GlaxoSmithKline, LVL, Mundipharma, Novartis, Pfizer, Pharm-Olam, Pliant Therapeutics, and Savara-Serendex. B.C. has received personal fees and nonfinancial support from AstraZeneca; grants, personal fees, and nonfinancial support from Boehringer Ingelheim and F. Hoffmann-La Roche, Ltd.; grants and personal fees from Sanofi; and personal fees from Bristol-Myers Squibb outside the submitted work. R.T. has received royalties for designing the Simple Evaluation of Food Intake $\left(\mathrm{SEFI}^{\circledR}\right)$ tool (K'noë Groupe GET, le Kremlin Bicêtre, France), and consulting fees from F. Hoffmann-La Roche, Ltd. M.L. has received fees, funding, or reimbursement for participation at meetings from AstraZeneca, Boehringer Ingelheim, Fresenius-Kabi, Guerbet, Roche SAS, and Siemens Healthcare. L.V. has received funding for research projects from Boehringer Ingelheim. M.Y. is an employee of Genentech, Inc. and a shareholder of F. Hoffmann-La Roche, Ltd. E.M. retired from employment at Genentech, Inc. in December 2020 and is a shareholder of F. Hoffmann-La Roche, Ltd. K.-U.K. is an employee and shareholder of F. Hoffmann-La Roche, Ltd. V.C. reports personal fees and nonfinancial support from Actelion; grants, personal fees, and nonfinancial support from Boehringer Ingelheim; personal fees from AstraZeneca, Bayer/MSD, Celgene, Galapagos, Galecto, Novartis, Sanofi, and Shionogi; and personal fees and nonfinancial support from F. Hoffmann-La Roche, Ltd. and Promedior (now a fully owned subsidiary of F. Hoffmann-La Roche, Ltd.) outside the submitted work.

\section{Funding Sources}

This analysis was sponsored by Genentech, Inc. and F. Hoffmann-La Roche, Ltd. 


\section{Author Contributions}

All authors were involved in the conception and/or design of the work and interpretation of study results, contributed to the manuscript from the outset, and read and approved the final draft. The analyses presented in this manuscript were performed by M.Y. and E.M. All authors vouch for the accuracy of the content included in the final manuscript.

\section{Data Availability Statement}

Qualified researchers may request access to individual patientlevel data through the clinical study data request platform (https:// vivli.org/). Further details on Roche's criteria for eligible studies are available here (https://vivli.org/members/ourmembers/). For further details on Roche's Global Policy on the Sharing of Clinical Information and how to request access to related clinical study documents, see here (https://www.roche.com/research_and_development/who_we_are_how_we_work/clinical_trials/our_commitment_to_data_sharing.htm).

\section{References}

1 Ley B, Collard HR, King TE Jr. Clinical course and prediction of survival in idiopathic pulmonary fibrosis. Am J Respir Crit Care Med. 2011;183:431-40.

2 Raghu G, Collard HR, Egan JJ, Martinez FJ, Behr J, Brown KK, et al. ATS/ERS/JRS/ALAT Committee on Idiopathic Pulmonary Fibrosis: an official ATS/ERS/JRS/ALAT statement: idiopathic pulmonary fibrosis: evidence-based guidelines for diagnosis and management. Am J Respir Crit Care Med. 2011;183:788-824.

3 Ryerson CJ, Collard HR. Update on the diagnosis and classification of ILD. Curr Opin Pulm Med. 2013;19:453-9.

4 American Cancer Society. Cancer facts \& figures 2020. 2020. Available from: https://www. cancer.org/content/dam/cancer-org/research/cancer-facts-and-statistics/annualcancer-facts-and-figures/2020/cancer-factsand-figures-2020.pdf Accessed 2021 Apr 23.

5 Ryerson CJ, Berkeley J, Carrieri-Kohlman VL, Pantilat SZ, Landefeld CS, Collard HR. Depression and functional status are strongly associated with dyspnea in interstitial lung disease. Chest. 2011;139:609-16.

6 Swigris JJ, Gould MK, Wilson SR. Health-related quality of life among patients with idiopathic pulmonary fibrosis. Chest. 2005;127: 284-94.

7 Collard HR, King TE Jr, Bartelson BB, Vourlekis JS, Schwarz MI, Brown KK. Changes in clinical and physiologic variables predict survival in idiopathic pulmonary fibrosis. Am J Respir Crit Care Med. 2003;168:538-42.

8 Ley B, Ryerson CJ, Vittinghoff E, Ryu JH, Tomassetti S, Lee JS, et al. A multidimensional index and staging system for idiopathic pulmonary fibrosis. Ann Intern Med. 2012;156: 684-91.

9 Celli BR, Cote CG, Marin JM, Casanova C, Montes de Oca M, Mendez RA, et al. The body-mass index, airflow obstruction, dyspnea, and exercise capacity index in chronic obstructive pulmonary disease. N Engl J Med. 2004;350:1005-12.

10 Baker JF, Billig E, Michaud K, Ibrahim S, Caplan L, Cannon GW, et al. Weight loss, the obesity paradox, and the risk of death in rheumatoid arthritis. Arthritis Rheumatol. 2015; 67:1711-7.
11 Ikeda S, Sekine A, Baba T, Katano T, Tabata E, Shintani R, et al. Negative impact of anorexia and weight loss during prior pirfenidone administration on subsequent nintedanib treatment in patients with idiopathic pulmonary fibrosis. BMC Pulm Med. 2019; 19:78.

12 Kulkarni T, Yuan K, Tran-Nguyen TK, Kim YI, de Andrade JA, Luckhardt T, et al. Decrements of body mass index are associated with poor outcomes of idiopathic pulmonary fibrosis patients. PLoS One. 2019;14: e0221905.

13 Nakatsuka Y, Handa T, Kokosi M, Tanizawa $\mathrm{K}$, Puglisi S, Jacob J, et al. The clinical significance of body weight loss in idiopathic pulmonary fibrosis patients. Respiration. 2018; 96:338-47.

14 Pugashetti J, Graham J, Boctor N, Mendez C, Foster E, Juarez M, et al. Weight loss as a predictor of mortality in patients with interstitial lung disease. Eur Respir J. 2018;52:1801289.

15 Jouneau S, Lederlin M, Vernhet L, Thibault R. Malnutrition in idiopathic pulmonary fibrosis: the great forgotten comorbidity! Eur Respir J. 2019;53:1900418.

16 Jouneau S, Kerjouan M, Rousseau C, Lederlin M, Llamas-Guttierez F, De Latour B, et al. What are the best indicators to assess malnutrition in idiopathic pulmonary fibrosis patients? A cross-sectional study in a referral center. Nutrition. 2019;62:115-21.

17 Cederholm T, Jensen GL, Correia MITD, Gonzalez MC, Fukushima R, Higashiguchi T, et al. GLIM core leadership committee, GLIM working group: GLIM criteria for the diagnosis of malnutrition: a consensus report from the global clinical nutrition community. Clin Nutr. 2019;38:1-9.

18 King TE Jr, Bradford WZ, Castro-Bernardini S, Fagan EA, Glaspole I, Glassberg MK, et al. The ASCEND Study: a randomized, doubleblind, placebo controlled trial of pirfenidone in patients with idiopathic pulmonary fibrosis (IPF) [poster]. Am Thorac Soc Int Conf. 2014

19 Noble PW, Albera C, Bradford WZ, Costabel U, Glassberg MK, Kardatzke D, et al. Pirfenidone in patients with idiopathic pulmonary fibrosis (CAPACITY): two randomised trials. Lancet. 2011;377:1760-9.
20 King TE Jr, Albera C, Bradford WZ, Costabel U, Hormel P, Lancaster L, et al. INSPIRE Study group: effect of interferon gamma- $1 \mathrm{~b}$ on survival in patients with idiopathic pulmonary fibrosis (INSPIRE): a multicentre, randomised, placebo-controlled trial. Lancet. 2009;374:222-8.

21 Swigris JJ, Ogura T, Scholand MB, Glaspole I, Maher TMK D, Kaminski J, et al. The RIFF Study (cohort A): a phase II, randomized, double-blind, placebo-controlled trial of lebrikizumab as monotherapy in patients with idiopathic pulmonary fibrosis [oral presentation]. Am Thorac Soc Int Conf. 2018;197: A6167.

22 World Health Organization. Body mass index: BMI. 2021. Available from: http://www. euro.who.int/en/health-topics/disease-prevention/nutrition/a-healthy-lifestyle/bodymass-index-bmi. Accessed 2021 Apr 23.

23 Food and Drug Administration. Developing products for weight management revision 1 : guidance for industry. 2007. Available from: https: //www.fda.gov/regulatory-information/search-fda-guidance-documents/developing-products-weight-management-revision-1. Accessed 2021 Apr 23.

24 Gray RJ. A Class of $K$-sample tests for comparing the cumulative incidence of a competing risk. Ann Stat. 1988;16:1141-54.

25 Jouneau S, Crestani B, Thibault R, Lederlin M, Vernhet L, Valenzuela C, et al. Analysis of body mass index, weight loss and progression of idiopathic pulmonary fibrosis. Respir Res. 2020;21:312.

26 Lee J, Martin-Schwarze A, Freiheit E, Yang M, Burg C. Association between clinical outcomes and baseline BMI or annualized weight loss in patients with idiopathic pulmonary fibrosis enrolled in the pulmonary fibrosis foundation patient registry [poster]. Chest. 2020;158:A105-34.

27 Jouneau S, Rousseau C, Lederline M, Kerjouan M, Guy T, Sohier L, et al. Low fat-free mass and body mass index are associated with worse survival in patients with idiopathic pulmonary fibrosis (IPF) [abstract]. Eur Respir J. 2019;54:PA1337. 
28 Ferrara G, Luppi F, Birring SS, Cerri S, Caminati A, Sköld M, et al. Best supportive care for idiopathic pulmonary fibrosis: current gaps and future directions. Eur Respir Rev. 2018; 27:170076.

29 Bouëtté G, Esvan M, Apel K, Thibault R. A visual analogue scale for food intake as a screening test for malnutrition in the primary care setting: prospective non-interventional study. Clin Nutr. 2021;40(1):174-80.

30 Glassberg MK, Wijsenbeek MS, Gilberg F, Petzinger U, Kirchgaessler KU, Albera C. Effect of pirfenidone on breathlessness in patients with idiopathic pulmonary fibrosis. Eur Respir J. 2019;54:1900399.

31 Jo HE, Glaspole I, Moodley Y, Chapman S, Ellis S, Goh N, et al. Disease progression in idiopathic pulmonary fibrosis with mild physiological impairment: analysis from the Australian IPF registry. BMC Pulm Med. 2018;18:19.
32 British Lung Foundation. What are the physical signs in the last weeks or days? 2021. Available from: https://www.blf.org.uk/support-for-you/end-of-life/physical-signs. Accessed 2021 Apr 23.

33 Zhao H, Wang Y, Qiu T, Liu W, Yao P. Autophagy, an important therapeutic target for pulmonary fibrosis diseases. Clin Chim Acta. 2020;502:139-47.

34 Hou J, Ma T, Cao H, Chen Y, Wang C, Chen $\mathrm{X}$, et al. TNF- $\alpha$-induced NF- $\mathrm{KB}$ activation promotes myofibroblast differentiation of LR-MSCs and exacerbates bleomycin-induced pulmonary fibrosis. J Cell Physiol. 2018;233:2409-19.

35 Mora AL, Bueno M, Rojas M. Mitochondria in the spotlight of aging and idiopathic pulmonary fibrosis. J Clin Invest. 2017;127:40514.
36 Piguet PF, Ribaux C, Karpuz V, Grau GE, Kapanci Y. Expression and localization of tumor necrosis factor-alpha and its mRNA in idiopathic pulmonary fibrosis. Am J Pathol. 1993; 143:651-5.

37 Weir NA, Poreddy M, Scully A, Nathan SD, Brown AW, Ahmad K, et al. Gender and BMI predict antifibrotic tolerance in IPF [poster A4259]. ATS. 2018;197:A4259.

38 Enomoto Y, Nakamura Y, Satake Y, Sumikawa H, Johkoh T, Colby TV, et al. Clinical diagnosis of idiopathic pleuroparenchymal fibroelastosis: a retrospective multicenter study. Respir Med. 2017;133:1-5.

39 Perelas A, Glennie J, van Kerkhove K, Li M, Scheraga RG, Olman MA, et al. Choice of antifibrotic medication and disease severity predict weight loss in idiopathic pulmonary fibrosis. Pulm Pharmacol Ther. 2019;59: 101839. 